\title{
Utilization pattern of traditional Chinese medicine for liver cancer patients in Taiwan
}

\author{
Yueh-Hsiang Liao ${ }^{1}$, Cheng-Chieh Lin ${ }^{2,3}$, Tsai-Chung Li, ${ }^{4,5^{*}+}$ and Jaung-Geng Lin ${ }^{1 *+}$
}

\begin{abstract}
Background: Traditional Chinese Medicine (TCM) is one of the most popular complementary and alternative medicine modalities worldwide. In Chinese and East Asian societies, TCM plays an active role in the modern health care system and is even covered by the National Health Insurance Program of Taiwan. Liver cancer is the second most common cancer in Taiwan. This study aimed to analyze the TCM utilization patterns of patients with liver cancer from 1996-2007 using a population-based random sample of one million insured patients.

Methods: A cross-sectional study was conducted using registration and claim data sets from 1996 to 2007 obtained from the Longitudinal Health Insurance Database 2005 (LHID2005). The outpatient datasets contained the encounter form-based dates of visit, three items from the International Classification of Diseases (Ninth Revision, Clinical Modification codes), the primary procedure (e.g., drug or diagnostic procedure), type of copayment, billed amount, and paid amount. Only ambulatory care was analyzed.
\end{abstract}

Results: A total of 6358 liver cancer patients utilized ambulatory care during the study period. Among them, 1240 (19.50\%) availed of TCM outpatient services. The prevalence of TCM use fluctuated during the study period, with a peak of $25.11 \%$ in 2001. After multivariable adjustment, the likelihood of TCM users was lower in participants aged 70 years and older (odds ratio, $\mathrm{OR}=0.79,95 \%$ confidence interval, $\mathrm{Cl}: 0.64-0.97)$ ), males ( $\mathrm{OR}=0.60,95 \% \mathrm{Cl}: 0.52-0.68$ ), residents of Taipei ( $\mathrm{OR}=0.75,95 \% \mathrm{Cl}: 0.58-0.96)$ as well as farmers and fishermen (OR=0.71, 95\% Cl: 0.54-0.94), but was higher in residents of central Taiwan ( $\mathrm{OR}=1.99,95 \% \mathrm{Cl}$ : 1.56-2.54. Most biomedicine and TCM outpatient services were provided by private clinics, followed by private hospitals. The two most frequently recorded coexisting diseases for both biomedicine and TCM outpatient visits specifically for liver cancer were (1) chronic liver disease and cirrhosis, and (2) malignant neoplasm of the liver and hepatic bile duct. The mean fee per visit for biomedicine was much higher than that for TCM, and the average expenditure was NT\$429.73 (US\$13.25) per biomedicine visit and NT\$301.93 (US\$9.32) per TCM visit (US\$1 = NT\$32.4 in 2007). For outpatient visits specifically for liver cancer, the mean fee per visit for biomedicine was much higher than that for TCM. The average cost per visit was NT\$1457.31 (US\$44.98) for biomedicine and NT\$1080.76 (US\$33.36) for TCM.

Conclusion: TCM was widely used by the patients with liver cancer, and the prevalence of TCM use remained stably high during the study period. The costs of insurance covering TCM were consistently lower than those covering biomedicine in patients with liver cancer. The findings of this study should be useful for health policy makers as well as researchers considering the integration of TCM and biomedicine.

\footnotetext{
* Correspondence: tcli@mail.cmu.edu.tw; jglin@mail.cmu.edu.tw

${ }^{\dagger}$ Equal contributors

${ }^{4}$ Graduate Institute of Biostatistics, College of Public Health, China Medical

University, Taichung, Taiwan

${ }^{1}$ Graduate Institute of Chinese Medicine, College of Chinese Medicine, China

Medical University, Taichung, Taiwan

Full list of author information is available at the end of the article
} 


\section{Introduction}

Incidence and mortality of liver cancer (LC)

LC is the leading cause of cancer-related mortality worldwide. Mongolia, Gambia, Taiwan, China, and Thailand have the highest incidence rates of LC in the world, and their age standardized incidence rates in 2008 were 94.4, 36.1, 35.7, 33.8, and 29.3 per 100000 persons, respectively [1]. In Taiwan, LC accounts for more than $28 \%$ of total deaths [2], and ranks as the second most common cancer in both men and women, accounting for about $20 \%$ of all cancer deaths. The annual standardized mortality incidence increased from 22.7/100 000 in 1991 to $26.2 / 100000$ in 2009 [2]. In China, LC accounts for more than $10 \%$ of total deaths and ranks as the fourth most common cancer [3].

\section{Use of Complementary and Alternative Medicine worldwide}

The use of Complementary and Alternative Medicine (CAM) has gained worldwide popularity. The motives for the use of CAM include perceived failure of standard health care, the need of a patient for autonomy, and preference for holistic or natural therapy in Western populations [4-6]. CAM is commonly used together with conventional medicine and has entered mainstream society and culture [7-9]. According to the 2007 National Health Interview Survey, the prevalence of CAM use is about $38 \%$ in American adults [9]. In a survey across a number of European countries, the percentages of CAM use range from $22.7 \%$ for head and neck cancer patients to $56.3 \%$ for pancreatic cancer patients [10].

\section{Use of Traditional Chinese Medicine (TCM) in Asian countries}

TCM is one of the most popular CAM forms worldwide. The motives for TCM use include cultural belief about TCM in managing illness symptoms, maximizing conventional treatment effect, and preventing recurrence in Chinese populations [11-13]. TCM is commonly used together with conventional medicine and has entered mainstream society and culture. In Chinese and East Asian societies, TCM plays an active role in the modern health care system. Unlike CAM that is not funded by either private or social insurance companies in most Western societies, TCM is covered by the National Health Insurance (NHI) Program of Taiwan. Thus, one important feature of the NHI Program is the coverage of both biomedicine (Western) and TCM. By 2003, after implementing the NHI Program, more than 99\% of the 23 million persons residing in Taiwan had been covered by this universal health insurance plan. Compared with CAM use by Western populations, TCM has a higher level of accessibility due to lesser financial barrier. A study on the determinants of TCM and acupuncture utilization of cancer patients in Taiwan has shown that the prevalence of TCM ranges from $14.81 \%$ for cervical cancer to $30.13 \%$ for breast cancer [8].

\section{Therapeutic effect of TCM against hepatocellular carcinoma (HCC) in previous studies}

Treatment with TCM has been investigated for its effect on the stimulation of host immune response that has cytotoxic activity against HCC. TCM is commonly used in combination with transcatheter arterial chemoembolization (TACE) to treat patients with unresectable HCC [14-16]. The findings of a meta-analysis of 37 randomized controlled trials involving 2653 patients reveal that TCM plus TACE improves patient survival, quality of life, alleviation of symptoms, and tumor response [14]. In another meta-analysis, TCM plus TACE significantly increases the survival, complete or partial response, non-deterioration performance, $\mathrm{T}$ cells, natural killer cells, and white blood cell count; significantly decreases the level of blood alpha-fetoprotein concentration; and significantly lowers the risk for nausea and vomiting [15]. A recent meta-analysis has also demonstrated that TCM plus TACE increases the proportions of cluster differentiation (CD) 3(+) T cells, CD4(+) T cells, and natural killer cells, as well as the ratio of $\mathrm{CD} 4(+) / \mathrm{CD} 8(+)$ before and after treatment [16]. A meta-analysis of randomized controlled trials for TCM combined with chemotherapy has reported promising evidence that TCM plus chemotherapy may benefit patients with HCC [17]. The most commonly used ingredients demonstrated to have oncologic and immunologic pharmacology are Astragalus, Panax ginseng, toad skin secretions (bufotoxin), beetle extracts (Mylabris), Atractylodes, Bupleurum, and Curcuma [18].

\section{How the current study helps resolve the uncertainties regarding TCM use}

Previous studies have explored the utilization of TCM either in a general population [19-24], in a single clinical setting [25], or for acupuncture use only [26]. Two studies have described the use frequencies, characteristics of users, and disease categories treated by TCM in Taiwan from 1996 to 2001 [27] and from 1997 to 2003 [28] using complete NHI datasets for TCM. A recent study has explored TCM use among all prostate cancer patients in the NHI datasets in 2007 [29]. However, TCM use among patients with LC has not yet been reported. This study aimed to compare the differences between the characteristics, types of care provider, existing diseases, and expenditures for outpatient services of TCM and non-TCM users with LC enrolled in the NHI Program in Taiwan from 1996 to 2007 using a population-based random sample of one million insured patients. 


\section{Methods}

\section{Data sources}

The NHI program was initiated in Taiwan in 1995 and currently covers about $99 \%$ of the 23 million population of Taiwan. The national government-run Bureau of National Health Insurance (BNHI) has contracted with $97 \%$ of all hospitals and $92 \%$ of all clinics nationwide. The BNHI conducts an expert review of random samples of every 50-100 ambulatory and inpatient claims in each hospital and clinic quarterly, and false reports of diagnosis are severely penalized [30]. The NHI Research Database (NHIRD) provides registration and claim datasets from a random sample of one million beneficiaries for use in research. The data for the present study was obtained from the Longitudinal Health Insurance Database 2005 (LHID2005), which was released by the Taiwan National Health Research Institute in 2007. The LHID2005 contains all ambulatory and inpatient claim data of one million beneficiaries who were randomly sampled from 23 million enrollees in the NHI. The distributions of the beneficiary age and gender in the LHID2005 and original NHI database are similar.

A retrospective study was conducted using the registration and claim datasets for the years 1996-2007 from the LHID2005. The LHID2005 database contains comprehensive information, such as demographic data, dates of clinical visits, diagnostic codes, expenditure amounts, and others. The amount of expenditure in the dataset was that covered by the NHI Program, which represented the consumption of medical resources. The NHI Program has a committee that reviews new treatments, drugs, and procedures, and only those that prove to have evidence-based effectiveness are covered. The expenditure can be classified into the following categories: fees for consultation, treatment, and medical supply; diagnosis fee; and drug fee. Files of registry for beneficiaries, ambulatory care expenditures by visits, and inpatient care by admission were obtained for analysis. To protect privacy, data on the patient identities and institutions were scrambled cryptographically by the NHIRD. Patients' privacy is under protection form using these data. Our study using these data are exempted from institutional review board approval of Public Health, Social and Behavioral Science Committee Research Ethics Committee, China Medical University and Hospital.

The NHI covered TCM outpatient care, but not inpatient care. Therefore, only TCM and biomedicine ambulatory care were analyzed in this study. The outpatient datasets contained encounter form-based date of visits, patient gender and date of birth, medical facility visited, department visited, prescribing physician, dispensing pharmacist, three items from the International Classification of Diseases, Ninth Revision, Clinical Modification (ICD-9-CM) codes, primary procedure (e.g., drug or diagnostic procedure), type of copayment, billed amount, and paid amount.

\section{Statistical analysis}

Continuous variables were reported as mean and 95\% confidence interval (CI), and categorical variables were reported as number, percentage, and 95\% CI. Differences in proportions and means were assessed using a $\chi^{2}$-test or a $t$-test. Adjusted odds ratios (ORs) were estimated by multivariate logistic regression analysis. Simple linear regression was used to examine the annual trend of TCM use in 1996-2007. All reported p values were those of two-sided tests. The statistical significance was set at $\mathrm{p}<0.05$. All analyses were performed using SAS version 9.1 (SAS Institute Inc., Cary, NC, USA).

\section{Results}

Prevalence of TCM use over time

A total of 6,358 LC patients used ambulatory care in 1996-2007. Among them, 1,240 (19.50\%) used TCM outpatient services. Figure 1 shows the prevalence of TCM use during the study period. The prevalence of TCM use fluctuated and had a peak of $25.11 \%$ in 2001 .

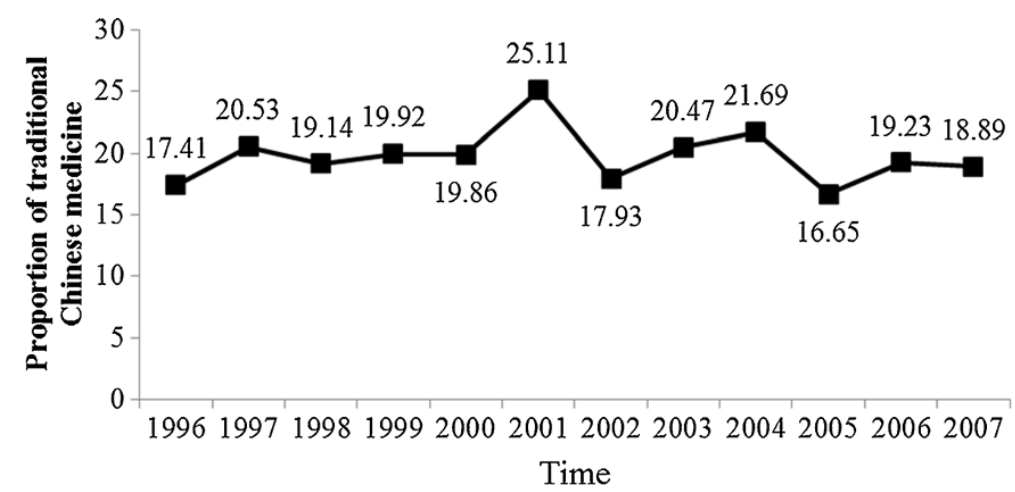

Figure 1 Proportion of traditional Chinese medicine use by liver cancer patients during the years 1996-2007. 
There was no significant linear trend $\left(R^{2}=0.0029\right.$, $\beta=-0.0369, p=0.8689$ ).

\section{Factors associated with TCM use}

The demographics are presented in Table 1 according to the status of TCM use. The mean patient age was 57.95 years $(\mathrm{SD}=11.46)$ for $\mathrm{TCM}$ users and 59.65 years $(\mathrm{SD}=12.30)$ for non-users. After multivariable adjustment, the likelihood of TCM users was lower in participants aged 70 years and older (odds ratio, $\mathrm{OR}=$ $0.79,95 \%$ confidence interval, CI: $0.64-0.97$, males $(\mathrm{OR}=0.60,95 \% \mathrm{CI}: 0.52-0.68)$, residents of Taipei $(\mathrm{OR}=$ 0.75 , 95\% CI: 0.58-0.96) as well as farmers and fishermen $(\mathrm{OR}=0.71,95 \% \mathrm{CI}: 0.54-0.94)$, but was higher in residents of central Taiwan $(\mathrm{OR}=1.99$, 95\% CI: $1.56-2.54)$. There was no significant difference between the insured amount and urbanization level of TCM users and nonusers. We further categorized TCM users into TCM only users and

Table 1 Liver cancer patient characteristics during the period 1996-2007

\begin{tabular}{|c|c|c|c|c|c|c|}
\hline \multirow[t]{2}{*}{ Characteristic } & \multicolumn{2}{|c|}{ TCM Nonusers } & \multicolumn{2}{|c|}{ TCM Users } & \multirow{2}{*}{$\begin{array}{c}\text { Adjusted }^{\mathrm{a}} \\
\text { OR }\end{array}$} & \multirow[t]{2}{*}{$95 \% \mathrm{Cl}$} \\
\hline & Total & $\%$ & Total & $\%$ & & \\
\hline Patient no. & 5118 & & 1240 & & & \\
\hline Age & \multicolumn{2}{|c|}{$59.65 \pm 12.30$} & \multicolumn{2}{|c|}{$57.95 \pm 11.46$} & & \\
\hline$<50$ (reference) & 1315 & 25.69 & 343 & 27.66 & 1.00 & \\
\hline $50 \mathrm{~s}$ & 1283 & 25.07 & 383 & 30.89 & 1.15 & $0.97-1.37$ \\
\hline $60 \mathrm{~s}$ & 1274 & 24.89 & 275 & 22.18 & 0.84 & $0.69-1.02$ \\
\hline$>=70 \mathrm{~s}$ & 1246 & 24.35 & 239 & 19.27 & 0.79 & $0.64-0.97$ \\
\hline \multicolumn{7}{|l|}{ Gender } \\
\hline Female (reference) & 1957 & 38.24 & 631 & 50.89 & 1.00 & \\
\hline Male & 3161 & 61.76 & 609 & 49.11 & 0.60 & $0.52-0.68$ \\
\hline \multicolumn{7}{|l|}{ Insured amount (NT\$/month) } \\
\hline$<20,000$ (reference) & 3491 & 68.21 & 815 & 65.73 & 1.00 & \\
\hline $20,000-39,999$ & 964 & 18.84 & 245 & 19.76 & 0.92 & $0.77-1.11$ \\
\hline $40,000-59,999$ & 459 & 8.97 & 121 & 9.76 & 1.01 & $0.78-1.30$ \\
\hline$>=60,000$ & 204 & 3.99 & 59 & 4.76 & 1.21 & $0.87-1.70$ \\
\hline \multicolumn{7}{|l|}{ Urban Level } \\
\hline 1 (reference) & 1456 & 29.19 & 348 & 28.74 & 1.00 & \\
\hline 2 & 1461 & 29.29 & 358 & 29.56 & 0.91 & $0.75-1.10$ \\
\hline 3 & 708 & 14.19 & 187 & 15.44 & 0.91 & $0.71-1.15$ \\
\hline 4 & 817 & 16.38 & 201 & 16.6 & 0.85 & $0.66-1.08$ \\
\hline$>=5$ & 546 & 10.95 & 117 & 9.67 & 0.80 & $0.58-1.08$ \\
\hline \multicolumn{7}{|l|}{ Residential Area } \\
\hline Northern (reference) & 667 & 13.03 & 149 & 12.02 & 1.00 & \\
\hline Taipei & 1923 & 37.57 & 383 & 30.89 & 0.75 & $0.58-0.96$ \\
\hline Central & 709 & 13.85 & 306 & 24.68 & 1.99 & $1.56-2.54$ \\
\hline Southern & 931 & 18.19 & 215 & 17.34 & 1.12 & $0.86-1.44$ \\
\hline Eastern & 89 & 1.74 & 28 & 2.26 & 1.40 & $0.83-2.36$ \\
\hline Kao-Ping & 783 & 15.3 & 153 & 12.34 & 0.91 & $0.69-1.18$ \\
\hline \multicolumn{7}{|l|}{ Insured unit } \\
\hline Government, school employees (reference) & 530 & 10.93 & 158 & 13.4 & 1.00 & \\
\hline Private enterprise employees & 1390 & 28.68 & 361 & 30.62 & 0.92 & $0.73-1.15$ \\
\hline Member of occupational & 960 & 19.81 & 271 & 22.99 & 0.99 & $0.77-1.27$ \\
\hline Farmers, fishermen & 1215 & 25.07 & 246 & 20.87 & 0.71 & $0.54-0.94$ \\
\hline Low-income households Veterans, other regional & 752 & 15.51 & 143 & 12.13 & 0.80 & $0.60-1.07$ \\
\hline
\end{tabular}

TCM: traditional Chinese Medicine; OR: odds ratio; Cl: confidence interval.

a: Adjusted ORs were from the model considering age, gender, insured amount, residential area, and insured unit. 
Table 2 Liver cancer outpatient service providers during the period 1996-2007

\begin{tabular}{|c|c|c|c|c|c|}
\hline \multirow{2}{*}{$\begin{array}{l}\text { Outpatient visits specifically for } \\
\text { liver cancer Characteristic }\end{array}$} & \multicolumn{2}{|c|}{ Biomedicine } & \multicolumn{2}{|c|}{ TCM users } & \multirow{2}{*}{$\frac{P \text { value for }}{x^{2}}$} \\
\hline & Visits & Percentage $(95 \% \mathrm{Cl})$ & Visits & Percentage $(95 \% \mathrm{Cl})$ & \\
\hline Type of providers & & & & & $<0.001$ \\
\hline Public hospitals & 75716 & $11.91(11.83-11.99)$ & 20455 & $8.98(8.86-9.1)$ & \\
\hline Public Chinese medicine hospitals & 34 & $0.01(0.01-0.01)$ & 636 & $0.28(0.26-0.30)$ & \\
\hline Private hospitals & 250469 & $39.40(39.28-39.52)$ & 70631 & 30.99 (30.80-31.18) & \\
\hline Private Chinese medicine hospitals & 326 & $0.05(0.04-0.06)$ & 2754 & $1.21(1.17-1.25)$ & \\
\hline Public clinics & 20175 & $3.17(3.13-3.21)$ & 4253 & $1.87(1.81-1.93)$ & \\
\hline Private clinics & 252442 & 39.71 (39.59-39.83) & 120067 & 52.69 (52.49-52.89) & \\
\hline Unknown & 36543 & $5.75(5.69-5.81)$ & 9098 & $3.99(3.91-4.07)$ & \\
\hline Total & 635705 & 100 & 227894 & 100 & \\
\hline
\end{tabular}

TCM: traditional Chinese medicine; $\mathrm{Cl}$ : confidence interval.

TCM plus biomedicine users. Their distributions along with those of biomedicine only users are shown in Additional file 1 .

\section{Medical institutes}

Most biomedicine outpatient services were provided by private clinics (39.71\%), followed by private hospitals (39.4\%) (Table 2). Similarly, the majority of TCM outpatient services were provided by private clinics (52.69\%) and private hospitals (30.99\%). The remaining TCM outpatient services were provided by public hospitals (8.98\%). The proportion of TCM outpatient services provided by private clinics was much higher than that of biomedicine outpatient services provided by private clinics $(52.69 \%$ vs. $39.71 \%, \mathrm{p}<0.001)$.

\section{Existing diseases}

The diagnoses in all ambulatory claim data were recorded in the ICD-9-CM format. The five most frequently recorded existing disease codes for biomedicine and TCM outpatient visits specifically for LC as well as for all outpatient visits are presented in Table 3. For outpatient visits specifically for LC, the four (out of five) most frequently recorded existing diseases for both biomedicine and TCM were (1) chronic liver disease and cirrhosis, (2) malignant neoplasm of the liver and hepatic bile ducts, (3) essential hypertension, and (4) acute upper respiratory infections. In contrast, diabetes mellitus was the third most frequently recorded existing disease for biomedicine, whereas general symptoms were the third most frequently recorded existing disease for TCM. For all outpatient visits, the four (out of five) most frequently recorded existing diseases for both biomedicine and TCM were (1) acute upper respiratory infection, (2) essential hypertension, (3) diabetes mellitus, and (4) general symptoms. In contrast, conjunctival disorders was the fifth most frequently recorded existing disease for biomedicine, whereas other and unspecified disorders of the back were the fourth most frequently recorded existing disease for TCM.

\section{Expenditures}

Table 4 shows the details of expenditures. Biomedicine outpatient services accounted for $72.73 \%$ of all outpatient visits and $77.61 \%$ of total expenditures, whereas TCM outpatient services accounted for $27.28 \%$ of visits and $22.39 \%$ of expenditures. The fees for consultation, treatment, and medical supplies, as well as drugs per visit for biomedicine were markedly higher than those for TCM. The average expenditure was NT\$429.73 (US\$13.25) per biomedicine visit and NT\$301.93 (US\$9.32) per TCM visit, and the average cost per visit was NT\$981.01 (US\$30.28) for biomedicine and NT\$754.38 (US\$23.28) for TCM ( $<0.001$ for all comparisons) (US\$1 = NT\$32.4 in 2007). The ratio of medical expenses for all biomedicine outpatient visits relative to that for TCM was 3.47 , whereas the ratio of the average medical expenses for each biomedicine outpatient visit relative to that for TCM was 1.3.

For outpatient visits specifically for LC, biomedicine outpatient services accounted for $73.61 \%$ of all visits and $79.00 \%$ of total expenditures, whereas TCM outpatient services accounted for $26.39 \%$ of visits and $21.00 \%$ of expenditures. The fees for consultation, treatment, and medical supplies, as well as drugs per visit for biomedicine were markedly higher than those for TCM. The average expenditure was NT\$739.58 (US\$22.83) per biomedicine visit and NT\$506.59 (US\$15.64) per TCM visit. The average cost per visit was NT\$1457.31 (US\$44.98) for biomedicine and NT\$1080.76 (US\$33.36) for TCM ( $\mathrm{p}<0.001$ for all comparisons). The ratio of medical expenses for all biomedicine outpatient visits relative to that for TCM was 3.76, whereas the ratio of the average medical expenses for each biomedicine outpatient visit relative to that for TCM was 1.35 . 
Table 3 Top 5 disease codes among liver cancer patients during the years 1996-2007 for all outpatient visits and outpatient visits specifically for liver cancer

\begin{tabular}{|c|c|c|c|c|c|c|}
\hline \multirow[b]{2}{*}{ Ranking } & \multicolumn{3}{|c|}{ Western medicine } & \multicolumn{3}{|c|}{ Traditional chinese medicine } \\
\hline & Disease (Code) & No. & Percentage $(95 \% \mathrm{Cl})$ & Disease (Code) & No. & Percentage $(95 \% \mathrm{Cl})$ \\
\hline \multicolumn{7}{|c|}{ Outpatient visits specifically for liver cancer } \\
\hline & \multicolumn{3}{|c|}{ Total $=1,181,130$} & \multicolumn{2}{|l|}{ Total $=384,074$} & \\
\hline 1 & $\begin{array}{l}\text { Chronic liver disease and } \\
\text { cirrhosis (571) }\end{array}$ & 84,263 & $7.31(7.26-7.36)$ & Chronic liver disease and cirrhosis (571) & 22,419 & $5.84(5.77-5.91)$ \\
\hline 2 & $\begin{array}{l}\text { Malignant neoplasm of the liver } \\
\text { and hepatic bile ducts (155) }\end{array}$ & 75,881 & $6.42(6.38-6.46)$ & $\begin{array}{l}\text { Malignant neoplasm of the liver } \\
\text { and hepatic bile ducts (155) }\end{array}$ & 1,9847 & $5.17(5.10-5.24)$ \\
\hline 3 & Diabetes Mellitus (250) & 49,506 & $4.19(4.15-4.23)$ & General symptoms (780) & 13,060 & $3.4(3.34-3.46)$ \\
\hline 4 & Essential hypertension (401) & 48,762 & $4.13(4.09-4.17)$ & Acute upper respiratory infections (465) & 12,231 & $3.18(3.12-3.24)$ \\
\hline 5 & $\begin{array}{l}\text { Acute upper respiratory } \\
\text { infections (465) }\end{array}$ & 40,502 & $3.43(3.40-3.46)$ & Essential hypertension (401) & 11,604 & $3.02(2.97-3.07)$ \\
\hline Ranking & Disease (Code) & No. & Percentage $(95 \% \mathrm{Cl})$ & Disease (Code) & No. & Percentage $(95 \% \mathrm{Cl})$ \\
\hline \multicolumn{7}{|c|}{ All outpatient visits } \\
\hline & Total $=86,850,726$ & \multicolumn{5}{|c|}{ Total $=29,277,941$} \\
\hline 1 & $\begin{array}{l}\text { Acute upper respiratory } \\
\text { infections (465) }\end{array}$ & $5,932,918$ & $6.84(6.83-6.85)$ & Acute upper respiratory infections (465) & $1,757,625$ & $6.00(5.99-6.01)$ \\
\hline 2 & Essential hypertension (401) & $3,884,150$ & $4.47(4.47-4.47)$ & General symptoms (780) & 857,752 & $2.93(2.92-2.94)$ \\
\hline 3 & Diabetes Mellitus (250) & $3,027,309$ & $3.49(3.49-3.49)$ & Essential hypertension (401) & 805,130 & $2.75(2.74-2.76)$ \\
\hline 4 & General symptoms (780) & $2,030,401$ & $2.34(2.34-2.34)$ & $\begin{array}{l}\text { Other and unspecified disorders } \\
\text { of the back ( } 724)\end{array}$ & 706,248 & $2.41(2.40-2.42)$ \\
\hline 5 & Disorders of conjunctica (372) & $1,642,787$ & $1.89(1.89-1.89)$ & Diabetes Mellitus (250) & 635,054 & $2.17(2.16-2.18)$ \\
\hline
\end{tabular}

\section{Discussion}

This study is the first large-scale survey focusing on TCM use among LC patients in Taiwan. The overall prevalence of insurance-covered TCM use in outpatient services among LC patients was $19.50 \%$ and remained stably high during the study period. TCM outpatient services accounted for $27.28 \%$ of the visits and $22.39 \%$ of the outpatient service expenditures of patients with LC. The costs of insurance covering TCM were consistently lower than those covering biomedicine.

The findings on the prevalence of TCM use in patients with LC were similar to those of previously studied patients with mild diseases or prostate cancer $[28,29]$. The prevalence of TCM utilization in our study was higher than that reported by Lin et al. [29] for patients with prostate cancer $(19.50 \%$ vs. $2.6 \%)$. One possible explanation is that TCM is more frequently used by patients with LC because the disease severity of LC requires more intensive treatment and patients with $\mathrm{LC}$ are inclined to seek alternative treatments. Another possible explanation is that only outpatient visits specific for prostate cancer have been considered in the study of Lin et al. [29], whereas all outpatient visits were considered in the current work.

Our results suggested that TCM services were utilized more often by females and residents of central Taiwan, but less often by patients $>70$ years old, residents of
Taipei, as well as farmers and fishermen. The higher TCM use of central Taiwan residents may probably be due to the higher availability of TCM providers in this area. Before 1998, the only medical university that provided formal TCM education was located in central Taiwan; thus, the ratio of TCM physicians to 10000 residents was 1090 for Taichung city in central Taiwan compared with 771 for the second highest area in 2010 . There are two possible reasons that can explain the low TCM use of farmers and fishermen. One is that farmers and fishermen live in areas with less access to TCM providers. Another is that their economic status is usually lower and the extra expenditure for TCM use may be a financial burden. Further research on the barriers for TCM use is warranted.

Based on the ICD-9-CM codes, we found that chronic liver disease and cirrhosis, as well as general symptoms were the primary indications for TCM. In biomedicine, the top two primary indications, apart from malignant neoplasm of the liver and hepatic bile ducts, were chronic liver disease and cirrhosis, as well as diabetes. These findings on the disease pattern of health care use may be explained by the fact that patients seek TCM to relieve symptoms. A recent systematic review of qualitative and quantitative studies regarding the views on traditional Chinese medicine amongst Chinese populations worldwide found that patients worldwide had a common 
Table 4 Expenditures for outpatient services for liver cancer patients (NT\$) during the period 1996-2007

\begin{tabular}{|c|c|c|c|c|c|c|c|c|c|}
\hline \multirow[b]{2}{*}{ Characteristic } & \multicolumn{3}{|c|}{ Biomedicine $(\mathrm{N}=53999777)$} & \multicolumn{3}{|c|}{ TCM $(N=20253460)$} & \multirow[b]{2}{*}{$\mathrm{t}$ value } & \multicolumn{2}{|c|}{$\begin{array}{l}\text { Biomedicine/ } \\
\text { TCM Ratio }\end{array}$} \\
\hline & Total & $\begin{array}{c}\text { Percentage } \\
(95 \% \mathrm{Cl})\end{array}$ & $\begin{array}{l}\text { Average } \\
(95 \% \mathrm{Cl})\end{array}$ & Total & $\begin{array}{l}\text { Percentage } \\
(95 \% \mathrm{Cl})\end{array}$ & $\begin{array}{l}\text { Average } \\
(95 \% \mathrm{Cl})\end{array}$ & & Total & Average \\
\hline \multicolumn{10}{|c|}{ Medical expenses for all outpatient visits } \\
\hline $\begin{array}{l}\text { Fees for consultation, } \\
\text { treatment, } \\
\text { andmedical supply }\end{array}$ & $23,205,324,170$ & $\begin{array}{c}43.8 \\
(43.8-43.8)\end{array}$ & $\begin{array}{c}429.73 \\
(429.71-429.75)\end{array}$ & $6,115,161,733.80$ & $\begin{array}{c}40.02 \\
(40.02-40.02)\end{array}$ & $\begin{array}{c}301.93 \\
(301.90-301.96)\end{array}$ & $226.64^{*}$ & 3.79 & 1.42 \\
\hline Diagnosis fee & $11,725,511,578$ & $\begin{array}{c}22.13 \\
(22.13-22.13)\end{array}$ & $\begin{array}{c}217.14 \\
(217.14-217.14)\end{array}$ & $4,425,149,296$ & $\begin{array}{c}28.96 \\
(28.96-28.96)\end{array}$ & $\begin{array}{c}218.49 \\
(218.49-218.49)\end{array}$ & $-59.07^{*}$ & 2.65 & 0.99 \\
\hline Drug fee & $18,043,485,487$ & $\begin{array}{c}34.06 \\
(34.06-34.06)\end{array}$ & $\begin{array}{c}334.14 \\
(334.13-334.15)\end{array}$ & $4,738,494,125$ & $\begin{array}{c}31.01 \\
(31.01-31.01)\end{array}$ & $\begin{array}{c}233.96 \\
(233.95-233.97)\end{array}$ & $388.04^{*}$ & 3.81 & 1.43 \\
\hline Total amount & $52,974,321,235$ & 100 & $\begin{array}{c}981.01 \\
(980.98-981.04)\end{array}$ & $15,278,805,154.80$ & 100 & $\begin{array}{c}754.38 \\
(754.35-754.41)\end{array}$ & $365.10^{*}$ & 3.47 & 1.30 \\
\hline & \multicolumn{3}{|c|}{ Biomedicine $(\mathrm{N}=635705)$} & \multicolumn{3}{|c|}{ TCM $(N=227894)$} & \multicolumn{3}{|c|}{$\begin{array}{l}\text { Biomedicine/ } \\
\text { TCM Ratio }\end{array}$} \\
\hline Characteristic & Total & $\begin{array}{l}\text { Percentage } \\
(95 \% \mathrm{Cl})\end{array}$ & $\begin{array}{l}\text { Average } \\
(95 \% \mathrm{Cl})\end{array}$ & Total & $\begin{array}{l}\text { Percentage } \\
(95 \% \mathrm{Cl})\end{array}$ & $\begin{array}{l}\text { Average } \\
(95 \% \mathrm{Cl})\end{array}$ & $t$ value & Total & Average \\
\hline \multicolumn{10}{|c|}{ Medical expenses for outpatient visits specifically for liver cancer } \\
\hline $\begin{array}{l}\text { Fees for consultation, } \\
\text { treatment, } \\
\text { andmedical supply }\end{array}$ & $470,152,992$ & $\begin{array}{c}50.75 \\
(50.75-50.75)\end{array}$ & $\begin{array}{c}739.58 \\
(739.32-739.84)\end{array}$ & 115449,750 & $\begin{array}{c}46.87 \\
(46.86-46.87)\end{array}$ & $\begin{array}{c}506.59 \\
(506.22-506.96)\end{array}$ & $29.19^{*}$ & 4.07 & 1.46 \\
\hline Diagnosis fee & $137,611,256$ & $\begin{array}{c}14.85 \\
(14.85-14.85)\end{array}$ & $\begin{array}{c}216.47 \\
(216.46-216.48)\end{array}$ & $50,252,360$ & $\begin{array}{c}20.40 \\
(20.39-20.40)\end{array}$ & $\begin{array}{c}220.51 \\
(220.5-220.52)\end{array}$ & $-16.35^{*}$ & 2.74 & 0.98 \\
\hline Drug fee & $318,652,124$ & $\begin{array}{c}34.40 \\
(34.40-34.40)\end{array}$ & $\begin{array}{c}501.26 \\
(501.13-501.39)\end{array}$ & $80,595,549$ & $\begin{array}{c}32.72 \\
(32.71-32.72)\end{array}$ & $\begin{array}{c}353.65 \\
(353.44-353.86)\end{array}$ & $33.91^{*}$ & 3.95 & 1.42 \\
\hline Total amount & $926,416,372$ & 100 & $\begin{array}{c}1457.31 \\
(1457.02-1457.60)\end{array}$ & $246,297,659$ & 100 & $\begin{array}{c}1080.76 \\
(1080.33-1081.19)\end{array}$ & $40.99^{*}$ & 3.76 & 1.35 \\
\hline
\end{tabular}

TCM: traditional Chinese medicine; *: $p<0.001 ; \mathrm{Cl}$ : confidence interval.

cultural affinity to TCM and considered TCM as an effective complement to western medicine (WM) for treating chronic or serious diseases [31]. Their finding may explain why LC patients in Taiwan like to seek TCM treatments for relieving their "general symptoms".

We observed that the proportions of hypertension and diabetes only accounted for a small portion of all ICD-9 codes made by patients with LC. Caution should be taken when interpreting these proportions. This proportion was affected by both the disease prevalence among Taiwanese LC patients and the rate of outpatient utilization for each disease by LC patients with co-existing conditions. This proportion is also related to insufficient comprehensive coding. For example, only three diseases were coded if a patient sought outpatient care for more than three diseases. Our data underestimated the proportion of existing disease among all ICD-9 codes.

Using data of liver cancer patients from a representative sample of Taiwan population, we found that women had higher TCM use than men. This finding is consistent with those that had been conducted in general population in Taiwan [32], patients with chronic noncommunicable disease [33] and patients with schizophrenia in Hong Kong [34]. Women have been found to be more predisposed to report their health as poor, which has been hypothesized that this result from women's health beliefs and help-seeking behavior [35]. There are two possible reasons why patients who aged 70 years and older or who were farmers and fishermen had lower TCM use than their counterparts. First, they lived in rural areas with lower density of medical services, especially TCM. Previous studies exploring the factors associated with TCM uses in Taiwan have found that people living in rural areas are less likely to access various conventional or unconventional therapies [28,36,37]. Second, the socioeconomic status (SES) of these individuals is usually low and low SES has been reported to be associated with low TCM use [38].

In Taiwan, the national health insurance program includes both biomedicine and TCM. Under two modalities of medicine within one health care system, it enhances the high availability and affordability of these two types of health care services, thus improves the quality, comprehensiveness, and efficiency of care. However, the majority of the TCM services were provided by the private sector. Public hospitals or clinics did not set up TCM departments until recent years because of popularity of TCM worldwide. Up to date, not all public 
hospitals or clinics provide TCM services. Most of patients who seek for health care service in public hospitals or clinics are veterans or individuals living in rural area or with low SES. It would increase the difficulty to bring biomedicine and TCM care together for those patients seeking care in public hospitals or clinics. Developing strategies to overcome the barrier for these individuals would be an important task for health care planners and policy makers.

The strength of this study is that it is the first largescale study of TCM use in Taiwanese society, and the $\mathrm{NHI}$ databases are representative of the general population in Taiwan because the NHI Program covers more than $99 \%$ of Taiwan's 23 million population and $93 \%$ of the medical institutes. Previous studies on health care utilization with regard to TCM/CAM use have been conducted with clinic attendees, telephone interviews, self-administered interviews, household interviews, as well as hospital and private clinic surveys. These studies usually have limited sample sizes, and have been conducted in countries in which TCM/CAM is not covered by insurance. Thus, the pattern and characteristics of TCM/CAM use may be affected by the socioeconomic status of individuals.

There are several limitations to this study. First, our study is a kind of administrative database research and uses ICD-9-CM codes to identify patients with LC and use drug and diagnosis procedure for care costs [39]. Misclassification errors from this type of research are inevitable. Second, some herbal medicines not covered by $\mathrm{NHI}$ and visits at clinics not under contract with the BNHI were not considered. About 10\% of TCM clinics are not under contract with the BNHI because the NHI payment is low. Some patients may also be taking decoction forms of Chinese medicine, which is not covered by the NHI Program. Hence, the NHIRD data may lead to an underestimation of TCM costs. Third, clinical and biochemical measurements, such as staging and alpha fetal protein, were not included in the study; thus, the TCM use and costs stratified by these factors cannot be explored.

\section{Conclusion}

The NHI Program of Taiwan is a comprehensive and universal health insurance program that covers both conventional biomedicine and TCM services. The prevalence of TCM use among LC patients remained stably high. The costs of insurance-covered TCM were consistently lower than those of biomedicine. This study provided information on TCM use frequency as well as coexisting diseases treated by biomedicine and TCM in LC patients, which should be useful to health policy makers and practitioners who consider the integration of TCM and biomedicine.

\section{Additional file}

Additional file 1: Table 1. Liver cancer patient Biomedicine and TCM services during the period 1996-2007.

\section{Abbreviations}

TCM: Traditional Chinese medicine; CAM: Complementary and alternative medicine; LHID2005: Longitudinal health insurance database 2005; ICD-9CM: International classification of diseases ninth revision, clinical modification; LC: Liver cancer; NHI: National health insurance; HCC: Hepatocellular carcinoma; TACE: Transcatheter arterial chemoembolization; CD: Cluster differentiation; BNHI: Bureau of national health insurance; NHIRD: NHI research database; SD: Standard deviation.

\section{Competing interests}

All authors have declared that they have no competing interest.

\section{Authors' contributions}

$Y H L, C C L$ and $T C L$ contributed equally to the design of the study and direction of its implementation, including supervision of the field activities, quality assurance and control. YHL and JGL supervised the field activities. JGL and TCL helped conduct the literature review and prepare the Methods and Discussion sections of the text. TCL and CCL designed the study's analytic strategy and conducted the data analysis. All authors read and approved the final manuscript.

\section{Acknowledgements}

This study was supported by the Taiwan Department of Health, China Medical University Hospital Cancer Research Center of Excellence (DOH101TD-C-111-005)

\section{Author details}

${ }^{1}$ Graduate Institute of Chinese Medicine, College of Chinese Medicine, China Medical University, Taichung, Taiwan. ${ }^{2}$ Department of Family Medicine, China Medical University Hospital, Taichung, Taiwan. ${ }^{3}$ School of Medicine, College of Medicine, China Medical University, Taichung, Taiwan. ${ }^{4}$ Graduate Institute of Biostatistics, College of Public Health, China Medical University, Taichung, Taiwan. ${ }^{5}$ Department of Health Care Administration, College of Health Science, Asia University, Taichung, Taiwan.

Received: 2 August 2011 Accepted: 31 August 2012 Published: 5 September 2012

\section{References}

1. Cancer Incidence, Mortality and Prevalence Worldwide in 2008 [http://globocan.iarc.fr]

2. Standardized cancer mortality from Department of Health, R.O.C. [http://www.doh.gov.tw/CHT2006/DM/DM2_2.aspx? now_fod_list_no=10642\&class_no=440\&level_no=3]

3. Hospital Authority Hong Kong Cancer Registry. [www3.ha.org.hk/cancereg/ C_stat.asp]

4. Eisenberg DM, Kessler RC, Foster C, Norlock FE, Calkins DR, Delbanco TL: Unconventional medicine in the United States: prevalence, costs, and patterns of use. N Engl J Med 1993, 328(4):246-252.

5. Astin JA: Why patients use alternative medicine: results of a national study. JAMA 1998, 279(19):1548-1553.

6. Hildreth $\mathrm{KD}$, Elman C: Alternative Worldviews and the Utilization of Conventional and Complementary Medicine. Sociol Inq 2007, 77(1):76-103.

7. Eisenberg DM, Davis RB, Ettner SL, Appel S, Wilkey S, Van Rompay M, Kessler RC: Trends in alternative medicine use in the United States, 1990-1997: results of a follow-up national survey. JAMA 1998, 280(18):1569-1575.

8. Pu CY, Lan VM, Lan CF, Lang HC: The determinants of traditional Chinese medicine and acupuncture utilization for cancer patients with simultaneous conventional treatment. Eur J Cancer Care (Engl) 2008, 17 (4):340-349.

9. Mehta DH, Phillips RS, Davis RB, McCarthy EP: Use of Complementary and Alternative Therapies by Asian Americans. Results from the National Health Interview Survey. J Gen Intem Med 2007, 22(6):762-767.

10. Molassiotis A, Fernadez-Ortega P, Pud D, Ozden G, Scott JA, Panteli V, Margulies A, Browall M, Magri M, Selvekerova S, Madsen E, Milovics L, 
Bruyns I, Gudmundsdottir G, Hummerston S, Ahmad AM, Platin N, Kearney $\mathrm{N}$, Patiraki E: Use of complementary and alternative medicine in cancer patients: a European survey. Ann Oncol 2005, 16(4):655-663.

11. Simpson PB: Family beliefs about diet and traditional Chinese medicine for Hong Kong women with breast cancer. Oncol Nurs Forum 2003, 30 (5):834-840.

12. Xu W, Towers AD, Li P, Collet JP: Traditional Chinese medicine in cancer care: perspectives and experiences of patients and professionals in China. Eur J Cancer Care (Engl). 2006, 15(4):397-403.

13. Cui $Y$, Shu XO, Gao Y, Wen W, Ruan ZX, Jin F, Zheng W: Use of complementary and alternative medicine by chinese women with breast cancer. Breast Cancer Res Treat 2004, 85(3):263-270.

14. Meng MB, Cui YL, Guan YS, Ying Z, Zheng MH, Yuan CK, Zhang RM: Traditional Chinese medicine plus transcatheter arterial chemoembolization for unresectable hepatocellular carcinoma. J Altern Complement Med 2008, 14(8):1027-1042.

15. Cho WC, Chen HY: Transcatheter arterial chemoembolization combined with or without Chinese herbal therapy for hepatocellular carcinoma: meta-analysis. Expert Opin Investig Drugs 2009, 18(5):617-635.

16. Meng MB, Wen QL, Cui YL, She B, Zhang RM: Meta-analysis: traditional Chinese medicine for improving immune response in patients with unresectable hepatocellular carcinoma after transcatheter arterial chemoembolization. Explore (NY) 2011, 7(1):37-43.

17. Shu X, McCulloch M, Xiao H, Broffman M, Gao J: Chinese Herbal Medicine and Chemotherapy in the Treatment of Hepatocellular Carcinoma: A Meta-analysis of Randomized Controlled Trials. Integr Cancer Ther 2005, 4 (3):219-229.

18. Wu P, Dugoua JJ, Eyawo O, Mills EJ: Traditional Chinese Medicines in the treatment of hepatocellular cancers: a systematic review and metaanalysis. J Exp Clin Cancer Res 2009, 28:112.

19. Chung V, Lau CH, Yeoh EK, Griffiths SM: Age, chronic non-communicable disease and choice of traditional Chinese and western medicine outpatient services in a Chinese population. BMC Health Serv Res 2009, 9:207.

20. Chung V, Wong E, Woo J, Lo SV, Griffiths S: Use of traditional Chinese medicine in the Hong Kong special administrative region of China. J Altern Complement Med 2007, 13(3):361-367.

21. Chi C, Lee JL, Lai JS, Chen SC, Chen CY, Chang SK: Utilization of Chinese medicine in Taiwan. Altern Ther Health Med 1997, 3(4):40-53.

22. Kang JT, Lee CF, Chen CF, Chou P: Factors related to the choice of clinic between Chinese traditional medicine and Western medicine. J Formos Med Assoc 1994, 93:549-555.

23. Chi C, Lee JL, Lai JS, Chen CY, Chang SK, Chen SC: The pratice of Chinese medicine in Taiwan. Soc Sci Med 1996, 43(9):1329-1348.

24. Chou P: Fators related to utilization of tradition Chinese medicine in Taiwan. Zhonghua Yi Xue Za Zhi(Taipei) 2001, 64(4):191-202.

25. Chen LC, Wang BR, Chou YC, Tein JH: Drug utilization pattern of Chinese herbal medicine in Taiwan. Pharmacoepidemiol Drug Saf 2005, 14(9): 651-657.

26. Chen FP, Kung YY, Chen TJ, Hwang SJ: Demographics and patterns of acupuncture use in the Chinese population: the Taiwan experience. $J$ Altern Complement Med 2006, 12(4):379-387.

27. Chen FP, Chen TJ, Kung YY, Chen YC, Chou LF, Chen FJ, Hwang SJ: Use frequency of traditional Chinese medicine in Taiwan. BMC Health Serv Res 2007, 7:26.

28. Chang LC, Huang N, Chou YJ, Lee CH, Kao FY, Huang YT: Utilization patterns of Chinese medicine and Western medicine under the National Health Insurance Program in Taiwan, a population -based study from 1997to 2003. BMC Health Serv Res 2008, 8:170

29. Lin YH, Chen KK, Chiu JH: Prevalence, Patterns, and Costs of Chinese Medicine Use Among Prostate Cancer Patients: A Population-Based Study in Taiwan. Integr Cancer Ther 2010, 9(1):16-23.

30. Chen HF, Ho CA, Li CY: Age and Sex May Significantly Interact With Diabetes on the Risks of Lower-Extremity Amputation and Peripheral Revascularization Procedures (Evidence from a cohort of a half-million diabetic patients). Diabetes Care 2006, 29(11):2409-2414

31. Chung VC, Ma PH, Lau CH, Wong SY, Yeoh EK, Griffiths SM: Views on traditional Chinese medicine amongst Chinese population: a systematic review of qualitative and quantitative studies. Health Expect 2012, 10:1369-7625
32. Chen FP, Chen TJ, Kung YY, Chen YC, Chou LF, Chen FJ, Hwang SJ: Use frequency of traditional Chinese medicine in Taiwan. BMC Health Serv Res 2007, 7:26.

33. Chung VC, Lau CH, Yeoh EK, Griffiths SM: Age, chronic non-communicable disease and choice of traditional Chinese and western medicine outpatient services in a Chinese population. BMC Health Serv Res 2009, 9:207.

34. Zhang ZJ, Tan QR, Tong Y, Wang XY, Wang HH, Ho LM, Wong HK, Feng YB, Wang D, Ng R, McAlonan GM, Wang CY, Wong VT: An epidemiological study of concomitant use of Chinese medicine and antipsychotics in schizophrenic patients: implication for herb-drug interaction. PLoS One 2011, 6(2):17239.

35. Bertakis KD, Azari R, Helms LJ, Callahan EJ, Robbins JA: Gender Differences in the Utilization of Health Care Service. J Fam Pract 2000, 49(2):147-152.

36. Shih CC, Su YC, Liao CC, Lin JG: Patterns of medical pluralism among adults: results from the 2001 National Health Interview Survey in Taiwan. BMC Health Serv Res 2010, 10:191.

37. Shih CC, Lin JG, Liao CC: Su YC:The utilization of traditional Chinese medicine and associated factors in Taiwan in 2002. Chin Med J (Engl) 2009, 122(13):1544-1548

38. Shih CC, Liao CC, Su YC, Yeh TF: Lin JG:The association between socioeconomic status and traditional chinese medicine use among children in Taiwan. BMC Health Serv Res 2012, 12:27.

39. van Walraven $C$, Bennett $C$, Forster AJ: Administrative database research infrequently used validated diagnostic or procedural codes. J Clin Epidemiol 2011, 64(10):1054-1059.

doi:10.1186/1472-6882-12-146

Cite this article as: Liao et al:: Utilization pattern of traditional Chinese medicine for liver cancer patients in Taiwan. BMC Complementary and Alternative Medicine 2012 12:146.

\section{Submit your next manuscript to BioMed Central and take full advantage of:}

- Convenient online submission

- Thorough peer review

- No space constraints or color figure charges

- Immediate publication on acceptance

- Inclusion in PubMed, CAS, Scopus and Google Scholar

- Research which is freely available for redistribution
Ciomed Central 